\title{
A PREDICTION MODEL OF THERMAL CONDUCTIVITY OF ROCK USING MEASUREMENTS IN BIPHASIC MIXTURES
}

\author{
Ariston de Lima Cardoso ${ }^{1}$, Roberto Max de Argollo² and Alexandre Barreto Costa ${ }^{3}$
}

\begin{abstract}
In this study, we developed a model to predict the thermal conductivity of full rocks from measurements on biphasic mixtures of grains of these rocks. Firstly, we measured the density and thermal conductivity of the full rock samples. The full samples were then grounded and we measured the effective thermal conductivity of mixtures prepared with grains of these rocks in different porosities using air as saturating. Using the flexible model of thermal conduction developed in this study, which we call Geoterm, and the rule of generalized mixture due to Korvin, we calculated the average values of the numerical factors of the equations of these two models and, with these equations, we predicted the thermal conductivity of the integrity rock by adjusting the equations of these models with experimental data. Even with these equations and the data of the integrity rocks and mixtures, we predicted the effective thermal conductivity of the samples for the various porosities of the mixtures. The predicted results for the full rock, as compared to the measured values, showed small and large discrepancies due to the large variation range of the thermal conductivity of the full rocks, resulting in ranges also wide for the numerical factors of the two equations. In agreement with Krupiczka empirical expression, the values predicted by the Geoterm and Korvin models for effective thermal conductivity showed lower discrepancies when compared to other models observed in this study.
\end{abstract}

Keywords: rock thermal conductivity, effective thermal conductivity, binary mixture model.

RESUMO. Neste estudo, desenvolvemos um modelo para predizer a condutividade térmica de rochas íntegras a partir de medidas em misturas binárias de grãos destas rochas. Primeiramente, medimos a densidade e a condutividade térmica das amostras das rochas íntegras. As amostras foram, em seguida, moídas e medimos a condutividade térmica efetiva de misturas preparadas com os grãos dessas rochas em diferentes porosidades usando ar como saturante. Usando o modelo flexível de condução térmica desenvolvido neste estudo, denominado Geoterm, e a regra da mistura generalizada de Korvin, calculamos os valores médios dos fatores numéricos das equações destes dois modelos e, com estas predissemos a condutividade térmica da rocha íntegra pelo ajuste dos parâmetros desses modelos com os dados experimentais. Ainda com essas equações e com os dados das rochas íntegras, como também das misturas, predissemos a condutividade térmica efetiva das amostras para as várias porosidades das misturas. Os resultados preditos para a amostra íntegra, quando comparados aos valores medidos, apresentaram discrepâncias pequenas e grandes, consequência de a faixa de variação da condutividade térmica das rochas ser bem larga resultando em faixas também largas para os fatores numéricos das duas equações. Em concordância com a expressão empírica de Krupiczka, os valores preditos pelos modelos Geoterm e Korvin para condutividade térmica efetiva mostraram menores discrepâncias quando comparados a outros modelos verificados neste estudo.

Palavras-chave: condutividade térmica de rocha, condutividade térmica efetiva, modelo de mistura binária.

\footnotetext{
${ }^{1}$ Universidade Federal do Recôncavo da Bahia, Centro de Ciências Exatas e Tecnologia, Campus de Santo Antônio de Jesus, BA, Brazil. Phone: +55(71) 9944-4425 - E-mail: ariston@ufrb.edu.br

2Universidade Federal da Bahia, Instituto de Física, Departamento de Física da Terra e do Meio Ambiente, Rua Barão de Jeremoabo, 40170-115 Salvador, BA, Brazil. Phone: +55(71) 3283-6680; Fax: +55(71) 3283-6681 - E-mail: robmax@ufba.br

3 Universidade Federal da Bahia, Instituto de Física, Departamento de Física da Terra e do Meio Ambiente, Rua Barão de Jeremoabo, 40170-115 Salvador, BA, Brazil. Phone: +55(71) 3283-6694; Fax: +55(71) 3283-6681 - E-mail: abc@ufba.br
} 


\section{INTRODUCTION}

Knowledge of the thermal properties of rocks is important in quantitative studies of sedimentary basin evolution to construct models that describe the thermal history of the basin. The thermal conductivity of rocks is commonly measured in solid samples with dimensions that are compatible with the measuring instrument. However, it is often necessary to make these measurements using fragmented rock samples. In the oil industry, for example, coring wells is expensive, and the thermal conductivity of sedimentary and crystalline rock samples must be determined using drill cuttings. To do so, mixtures of the ground samples are prepared, and models are used to obtain the thermal conductivity from measurements of the effective thermal conductivity (ETC) of the mixtures. The conductivity of the rock grains depends on several factors, such as the mineralogical composition, texture, structure, type and amount of fluid saturation, density, anisotropy and porosity. These parameters and properties, which are closely related to the formation processes of the minerals and rocks, make the determination of the thermal properties of fragmented samples a complex task that requires theoretical or empirical modeling.

Petrophysical studies often require ETC measurements of binary mixtures of rock grains that are saturated by air. Several models and formulations have been proposed to predict such measurements; all of them combine the porosity of the mixture and the thermal conductivity of the mixed phases, and some include an empirical factor. However, the appropriate model for a given mixture is not always clear. Of the models available in the literature, some have been applied to sedimentary rocks (e.g., Anand et al., 1973; Tenchov, 1998), while others have been applied to sands (e.g., Tavman, 1996). We are not aware of models that have been applied to igneous and metamorphic rocks.

In this paper, we develop a model to predict thermal conductivity of full rocks from measurements on binary mixtures of grains of these rocks. Firstly, we made measurements in the whole samples; then, the samples were ground and prepared mixtures with the grains. The samples were collected from outcrops of basement rocks on the northeast Brazilian coast. The lithologies analyzed in this work include granite, gneiss, orthoderived rocks and metasandstone.

This work is part by the Geoterm-Ne project, under which the samples were collected, funded by Petrobras-Cenpes-Promob and by the National Institute of Science and Technology of Petroleum Geophysics - INCT-GP.

\section{Thermal Measurements and Effective Thermal Conductivity Models}

Thermal conductivity measurements are usually made by studying the transient behavior of a heat pulse that is injected into the material. In granular materials, the irregularities, heterogeneity and roughness of the grains complicate the heat transfer mechanism in the mixture. The heat is transported by conduction in the solid grains and in the fluid, by convection in the fluid and by radiation between the grains. The heat transport by radiation is negligible in mixtures of small grains at temperatures below $200^{\circ} \mathrm{C}$; and the convection of heat is negligible in grains with diameters less than $1 \mathrm{~cm}$ (Woodside, 1958 apud Woodside \& Messmer, 1961). In this study, we neglect the effects of radiation and convection and consider small grains (less than $3 \mathrm{~mm}$ ) at room temperature.

In conductive transport, the heat pulse propagates through the pores and grains of the mixture, and the driving mechanism of the heat transfer depends on the relationships between the thermal properties of the solid grains and the saturating fluid. For mixtures in which the thermal conductivity of the solid is greater than that of the fluid, most of the heat is conducted through the solid grain contacts. This type of mixture is defined by some authors as external porosity. When the thermal conductivity of the solid is less than that of the fluid, heat flows primarily in the fluid phase, and the porosity is said to be internal (e.g., Carson et al., 2005).

Mixture models can be described by combining the values of the quantity to be determined in the solid samples with the volume fraction of each material in the mixture. In a mixture that contains n elements with the same physical property $G_{i}$ and volume fraction $\phi_{i}$, Lichtenecker \& Rother (1931) apud Tenchov (1998) and Korvin (1982) showed that the physical property of the mixture $G$ can be represented by:

$$
\begin{aligned}
G & =\left[\sum_{l}^{n} \phi_{i} G_{i}^{t}\right]^{l / t} \text { when } t \neq 0 \\
G & =\exp \left(\sum_{l}^{n} \phi_{i} \ln G_{i}\right) \text { when } t=0,
\end{aligned}
$$

and

$$
\sum_{l}^{n} \phi_{i}=1,
$$

where $t$ is a real number called of geometric distribution factor. 
From Eq. (1a), in a binary mixture that consists of solid grains with a thermal conductivity $\lambda_{s}$ that is uniformly distributed in a host fluid with a thermal conductivity $\lambda_{a}$, the (ETC) $\lambda_{e f}$ is expressed by

$$
\lambda_{e f}\left[\phi \lambda_{a}^{t}+(1-\phi) \lambda_{s}^{t}\right]^{l / t} .
$$

Korvin (1982) developed the general mixture rule using the theory of functional equations under appropriate boundary conditions and showed that Eq. (2) is exact and represents the only function for a two-phase composite with $t, t \neq 0$, some arbitrary real number in $(-\infty,+\infty)$.

Several models and expressions have been proposed to predict the ETC in binary mixtures as a function of the thermal conductivity of each phase and the porosity. Most of these models are based on a few basic structural models, specifically the series, parallel, geometric, Maxwell (in its many forms) and effective medium theory (EMT) models. In the series (Eq. (3)), parallel (Eq. (4)) and geometric (Eq. (5)) models, the ETC is given by the weighted harmonic, weighted arithmetic and geometric weighted means, respectively, of the two phases of the mixture:

$$
\begin{aligned}
\lambda_{e f} & =\frac{1}{\phi / \lambda_{a}+(1-\phi) / \lambda_{s}} \\
& =\frac{\lambda_{a} \lambda_{s}}{(1-\phi) \lambda_{a}+\phi \lambda_{s}}, \\
\lambda_{e f} & =\phi \lambda_{a}+(1-\phi) \lambda_{s} \\
\lambda_{e f} & =\lambda_{a}^{\phi} \lambda_{s}^{1-\phi}
\end{aligned}
$$

Eqs. (3) to (5) can be obtained from the Korvin model (Eq. (2)) with $t=-1$ (series model), $t=1$ (parallel model) and $t=0$ (geometric model), respectively; the latter is the limit of Eq. (2) by the L'Hospital rule. In the series and parallel models, the phases in the mixture are arranged in layers that are perpendicular and parallel to the direction of heat flow, respectively, while in the geometric model, the phases are randomly distributed. The series and parallel models therefore define the minimum and maximum limits of the ETC of a mixture in which the volume fractions and the thermal conductivities of the components are accurately known and heat transport is only conductive (Carson et al., 2006).

The Maxwell model (Maxwell, 1954) yields an exact solution for the effective electrical conductivity for small spheres dispersed within a continuous medium when the spheres are far enough apart to not interact with each other. The Maxwell-Eucken (Eucken, 1940 apud Carson et al., 2006; Maxwell, 1954) model is the Maxwell model applied to thermal conductivity; in it, the spheres are sufficiently far apart that local variations in the temperature around each sphere do not interfere with the temperatures around the neighboring spheres.

In binary mixtures, the Maxwell-Eucken model (ME) is divided into two models: the inferior ME model (ME-I) for external porosity mixtures, in which the solid is the dispersed phase and air is the continuous phase (Eq. (6)):

$$
\lambda_{e f}=\lambda_{a} \frac{3 \lambda_{s}-2\left(\lambda_{s}-\lambda_{a}\right) \phi}{3 \lambda_{a}+\left(\lambda_{s}-\lambda_{a}\right) \phi}
$$

and the superior ME model (ME-S) for internal porosity mixtures, where the solid is the continuous phase (Eq. (7)):

$$
\lambda_{e f}=\lambda_{s} \frac{3 \lambda_{s}+\left(\lambda_{a}-\lambda_{s}\right)(1+2 \phi)}{3 \lambda_{s}+\left(\lambda_{a}-\lambda_{s}\right)(1-\phi)} .
$$

The EMT model (Landauer, 1952) assumes a completely random distribution for all phases and is described by the sum

$$
\sum_{i} \phi_{i} \frac{\lambda_{i}-\lambda_{e f}}{\lambda_{i}+2 \lambda_{e f}}=0
$$

For a binary mixture of solid grains with air as the saturant the EMT model can be expressed by Eq. (9) which lies within the Korvin bounds and the Maxwell-Eucken limits. It is an identifier

$$
\begin{gathered}
\lambda_{e f}=\frac{1}{4}\left\{(3 \phi-1) \lambda_{a}-(3 \phi-2) \lambda_{s}\right. \\
\left.+\sqrt{\left[(3 \phi-1) \lambda_{a}-(3 \phi-2) \lambda_{s}\right]^{2}+8 \lambda_{a} \lambda_{s}}\right\} .
\end{gathered}
$$

that can be used to characterize a mixture as internal or external porosity; those mixtures that lie between the ME-I and EMT models are external porosity mixtures, and those that lie between the EMT and ME-S models are internal porosity mixtures (Carson et al., 2005).

Figure 1 shows ETC versus porosity graphs for the models described above. The parallel (curve a) and series (curve f) models define boundaries that enclose all of the other models; these curves correspond to the Korvin model for $t=1$ and $t=-1$, respectively, and thus represent the maximum and minimum bounds of the ETC for a biphasic mixture. Curves (b) and (e) represent models ME-S and ME-I, respectively, which define stricter limits within the Korvin bounds. Internal porosity mixtures plot in the region between curves (b) and (c), and mixtures of external porosity fall between curves (c) and (e). Curve (d) represents the geometric model, which coincides with the Korvin model at $t=0$. 


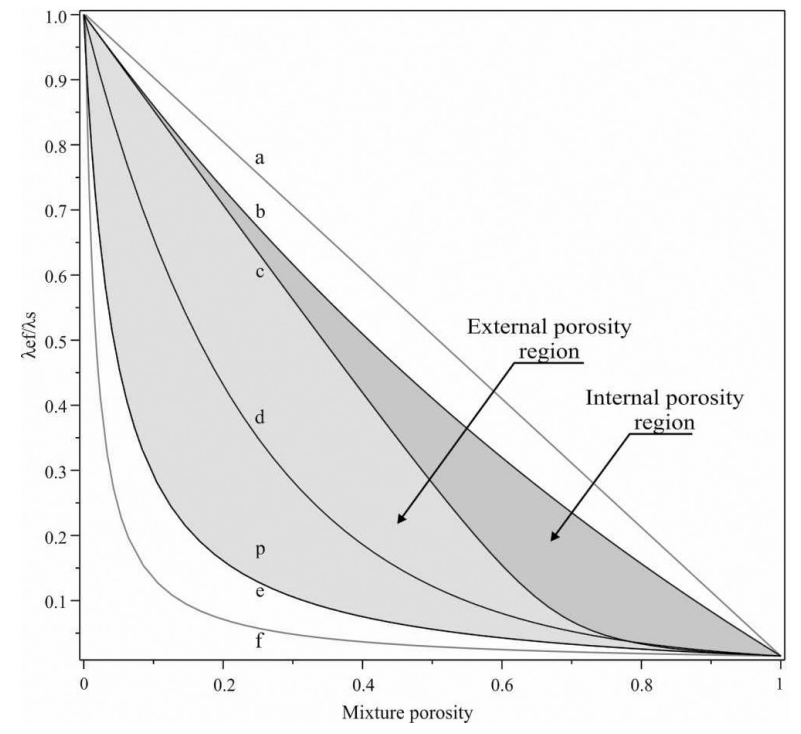

Figure 1 - ETC graphs of the models: (a) parallel; (b) superior Maxwell-Eucken; (c) effective medium theory (EMT); (d) geometric; (e) inferior Maxwell-Eucken; (f) series. Curves (a) and (f) define the Korvin bounds; curves (b) and (e) are the ME limits of the Maxwell-Eucken's model; curves (b) and (c) define the region of internal porosity; and curves (c) and (e) define the region of external porosity. $\left(\lambda_{s} / \lambda_{a}=100\right)$.

\section{Empirical expressions}

Many empirical expressions have been proposed for the ETC of granular binary mixtures. Krupiczka (1967) obtained numerical solutions for the ETC of granular materials for a model consisting of long cylinders and another consisting of spheres in a cubic lattice. He correlated the solutions of these models by taking into account the porosity and derived the equation:

$$
\lambda_{e f}=\lambda_{f}\left(\lambda_{s} / \lambda_{f}\right)^{A+B \log \left(\lambda_{s} / \lambda_{f}\right)}
$$

with $A=0.280-0.751 \log \phi$ and $B=-0.057 A$. Eq. (10) is valid for $0.215 \leq \phi \leq 0.476$.

Woodside \& Messmer (1961) constructed a modified resistor model to predict the ETC of porous media by combining series and parallel models and using the electrical conductivity of an aggregate of conductive particles saturated with an electrolytic conductor as an analog. The equation obtained for the ETC in this model is

$$
\lambda_{e f}=\frac{a \lambda_{f} \lambda_{s}}{\lambda_{s}(1-d)+d \lambda_{f}}+c \lambda_{f}
$$

where $c=\phi-0.03, a=(1-c)$ and $d=((1-\phi) / a)$ and $c$ is taken from Stephenson \& Woodside (1958) apud Woodside \& Messmer (1961).

\section{Flexible models}

Models described by only the thermal conductivities $\phi_{i}$ and volume fractions $\phi_{i}$ are referred to as rigid models, while those involving an additional parameter are referred to as flexible models. Krischel's model (Krischel, 1963 apud Carson et al., 2006) is the most commonly used flexible ETC model. This model, which is expressed by Eq. (12), combines the series and parallel models with a numerical factor $p$ known as a weighting factor. Krischel's model reduces to the series model for $p=0$ and to the parallel model for $p=1$, so the graph of Eq. (12) lies within the entire region between the Korvin bounds when $p$ varies from 0 to 1 . Many other flexible models that can cover the Korvin region by choosing different values of the parameter $p$ have been proposed (see Carson et al., 2006). Because these models can be constructed for any experimental points by adjusting the parameter $p$, they allow for better performance than other models. The problem is choosing a value for the weighting factor $p$. Several studies have attempted to correlate the factor $p$ with characteristics such as the shape, dimensions and porosity of the grains, but these correlations are dependent on empirical constants; because $p$ is determined empirically, the correlations are not generally valid.

$$
\lambda_{e f}=\frac{(1-p) \lambda_{f} \lambda_{s}}{(1-\phi) \lambda_{f}+\phi \lambda_{s}}+p\left[\phi \lambda_{f}+(1-\phi) \lambda_{s}\right]
$$

\section{METHODOLOGY}

The 19 rock samples analyzed in this work, including six granites (Gr), four gneisses (Gn), four orthoderived rocks (Or) and five metasandstones $(\mathrm{Me})$, were collected from basement outcrops along the northeastern Brazil coastline during the project Geoterm-Ne. In these whole rock samples, we analyzed the mass density and the thermal conductivity. The mass density was determined with a water pycnometer developed by Oliveira (2006) which provides measurement precision of $0.2 \%$. The thermal conductivity was measured with a thermal properties analyzer, a Quickline-30, equipped with a planar type sensor covering a range from 0.1 to $6.0 \mathrm{~W} \mathrm{~m}^{-1} \mathrm{~K}^{-1}$ in a laboratory with temperature stabilized in $22^{\circ} \mathrm{C}$. Rock samples were kept in the laboratory for at least $48 \mathrm{~h}$ before being measured to acquire the same temperature. We made measurements on well polished faces to reduce the effect of thermal contact resistance between the sensor and the rock material. To account for the possible effects of anisotropy, we made measurements on two mutually perpendicular polished faces to obtain average values of the thermal rock conductivity. We made a minimum of three measurements on each face and 
take the average value to minimize effects of the heterogeneity of the rock. The precision for the thermal conductivity measurement is $10 \%$.

After these analyses were performed, the whole rock samples were ground to grains with size of medium sand. We prepared binary mixtures of the dried grains in a cylindrical container $60 \mathrm{~mm}$ in diameter and $140 \mathrm{~mm}$ high using air as saturant. To obtain the porosity, we calculated the volume of the mixture by measuring its mass and using the density determined from the whole sample. The porosity of the mixture was changed by compressing the mixture in the cylinder to ensure a homogeneous density throughout the column. This preparation allows an error of about $3 \%$ for the porosity determination.

For each sample, we measured the ETC using the same analyzer equipped with a needle sensor for the range from 0.2 to $1.0 \mathrm{~W} \mathrm{~m}^{-1} \mathrm{~K}^{-1}$. The needle is $105 \mathrm{~mm}$ long, $0.8 \mathrm{~mm}$ in diameter and has a heat source at its midpoint together with a thermistor to monitor the temperature. The needle was introduced into the cylinder through an orifice at its bottom so that it is completely involved by the mixture. For each sample, we measured the thermal conductivity for at least three porosity values to verify the behavior between conductivity and porosity. The measures in the mixtures were made in the laboratory with permanently stabilized temperature, and the precision for the ETC measurements is $10 \%$.

\section{RESULTS AND DISCUSSION}

Table 1 presents the specific gravity $(\rho)$ and average thermal conductivity $\left(\lambda_{s}\right)$ measurements obtained in full rock samples as well as the porosity $(\phi)$ and the ETC determined in the mixtures. The error in the measurements of density and thermal conductivity are $0.5 \%$ and $10 \%$ respectively. As described above, we measured the ETC for a minimum of three porosity values of each mixture. The porosities of the samples were between 0.262 and 0.505 , and the ETC values ranged from 0.188 to $0.392 \mathrm{~W} \mathrm{~m}^{-1} \mathrm{~K}^{-1}$.

In Figure 2, the experimental results from Table 1 are plotted on the ETC graphs from Figure 1. Should be noted that about twothirds of these points corresponds to measurements of a same sample at different porosities. Figure 2 shows that all of the measurements lie within the Korvin model, which characterizes the mixtures as binary. In addition, the measurements fall between the EMT and ME-I models, which characterizes the mixtures as external porosity one; this indicates that the heat conduction in these mixtures is primarily through the rock grains.

In Figure 2, it is observed that all of the points lie between the curves of the geometric and ME-I models. The orthoderived and metasandstone rock samples plot across the bottom of the region formed by these two models, while the gneisses plot further to the top and the granite plots in the central region. In general, however, the distribution appears to be independent of lithology.

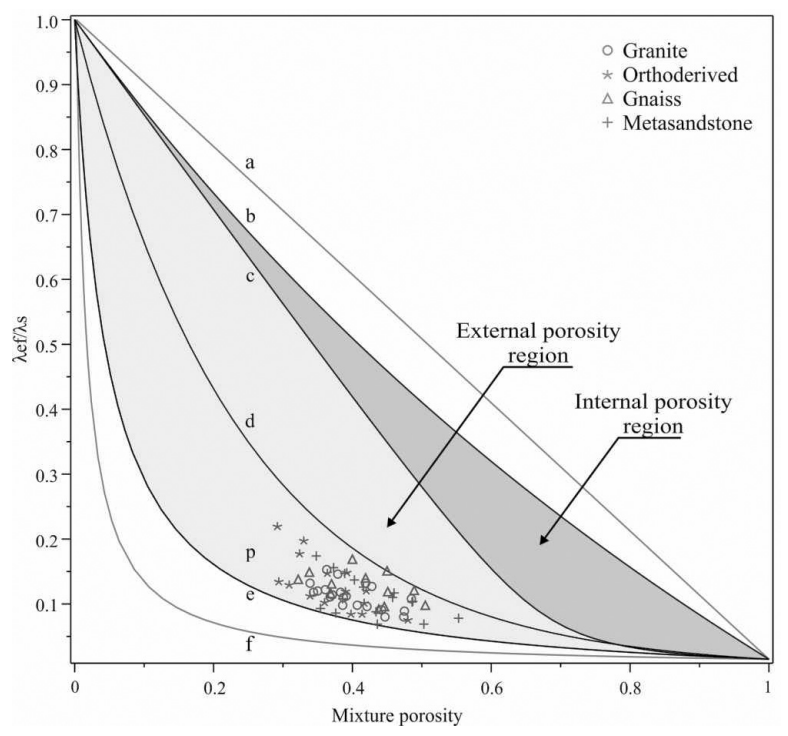

Figure 2 - Data from Table 1 plotted on the ETC graphs from Figure 1. $\lambda_{s} / \lambda_{a}=100$.

The observation that the ETC values measured in the binary mixtures of rock grains from diverse lithologies and with a broad spectrum of thermal conductivity occupy a limited region on the graph led us to build a flexible type thermal conduction model type that is more spatially restricted than the Korvin model in an attempt to achieve more accurate results for the ETC of these mixtures. This new model, which we call Geoterm, is expressed by Eq. (13) and combines the geometric (Eq. (5)) and inferior Maxwell-Eucken (Eq. (6)) models with a weighting factor $p$ : for $p=0$, Geoterm reduces to the ME-I model, and for $p=1$, Geoterm reduces to the geometric model. The graph of Eq. (13) lies in the region between the curves of these two models when $p$ varies from 0 to 1 .

$$
\begin{gathered}
\lambda_{e f}=(1-p) \lambda_{f} \frac{-2\left(\lambda_{f}-\lambda_{s}\right)(1-\phi)}{2 \lambda_{f}+\lambda_{s}} \\
+\left(\lambda_{f}-\lambda_{s}\right)(1-\phi) \\
+p \lambda_{f}^{\phi} \lambda_{s}^{1-\phi} .
\end{gathered}
$$

These two models were chosen because the points plotted between their curves (see Fig. 2) and because the monotonic behaviors of these curves were similar, particularly in the porosity 
Table 1 - Density $\left(\rho, \mathrm{kg} \mathrm{m}^{-3}\right)$ and thermal conductivity $\left(\lambda_{s}, \mathrm{~W} \mathrm{~m}^{-1} \mathrm{~K}^{-1}\right)$ measurements in whole rock samples and porosity $(\phi)$ and $\operatorname{ETC}\left(\lambda_{e f}, \mathrm{~W} \mathrm{~m}^{-1} \mathrm{~K}^{-1}\right)$ measurements in the mixtures.

\begin{tabular}{|c|c|c|c|c|c|c|c|c|c|}
\hline Sample & $\rho$ & $\lambda_{s}$ & $\phi$ & $\lambda_{e f}$ & Sample & $\rho$ & $\lambda_{s}$ & $\phi$ & $\lambda_{e f}$ \\
\hline Gr 01 & 2,588 & 2.11 & 0.467 & 0.228 & $\mathrm{Gn} 10$ & 2,647 & 2.54 & 0.338 & 0.378 \\
\hline Gr 01 & 2,588 & 2.11 & 0.428 & 0.268 & Or 11 & 2,509 & 1.75 & 0.391 & 0.260 \\
\hline Gr 01 & 2,588 & 2.11 & 0.419 & 0.278 & Or 11 & 2,509 & 1.75 & 0.329 & 0.346 \\
\hline Gr 01 & 2,588 & 2.11 & 0.379 & 0.308 & Or 11 & 2,509 & 1.75 & 0.291 & 0.385 \\
\hline Gr 01 & 2,588 & 2.11 & 0.363 & 0.323 & Or 12 & 2,650 & 2.01 & 0.419 & 0.243 \\
\hline Gr 02 & 2,663 & 2.20 & 0.475 & 0.195 & Or 12 & 2,650 & 2.01 & 0.363 & 0.298 \\
\hline Gr 02 & 2,663 & 2.20 & 0.383 & 0.259 & Or 12 & 2,650 & 2.01 & 0.323 & 0.358 \\
\hline Gr 02 & 2,663 & 2.20 & 0.339 & 0.291 & Or 13 & 2,839 & 3.35 & 0.479 & 0.255 \\
\hline Gr 03 & 2,638 & 2.69 & 0.474 & 0.216 & Or 13 & 2,839 & 3.35 & 0.416 & 0.341 \\
\hline Gr 03 & 2,638 & 2.69 & 0.421 & 0.257 & Or 13 & 2,839 & 3.35 & 0.389 & 0.402 \\
\hline Gr 03 & 2,638 & 2.69 & 0.387 & 0.296 & Or 14 & 2,616 & 2.91 & 0.397 & 0.261 \\
\hline Gr 03 & 2,638 & 2.69 & 0.371 & 0.308 & Or 14 & 2,616 & 2.91 & 0.293 & 0.392 \\
\hline Gr 04 & 2,603 & 2.66 & 0.442 & 0.242 & Or 14 & 2,616 & 2.91 & 0.308 & 0.379 \\
\hline Gr 04 & 2,603 & 2.66 & 0.391 & 0.299 & Or 14 & 2,616 & 2.91 & 0.413 & 0.246 \\
\hline Gr 04 & 2,603 & 2.66 & 0.361 & 0.325 & Or 14 & 2,616 & 2.91 & 0.359 & 0.299 \\
\hline Gr 05 & 2,578 & 2.85 & 0.407 & 0.279 & Or 14 & 2,616 & 2.91 & 0.338 & 0.329 \\
\hline Gr 05 & 2,578 & 2.85 & 0.368 & 0.315 & Me 15 & 2,583 & 2.19 & 0.457 & 0.244 \\
\hline Gr 05 & 2,578 & 2.85 & 0.344 & 0.336 & Me 15 & 2,583 & 2.19 & 0.402 & 0.303 \\
\hline Gr 06 & 2,593 & 3.00 & 0.447 & 0.239 & Me 15 & 2,583 & 2.19 & 0.347 & 0.384 \\
\hline Gr 06 & 2,593 & 3.00 & 0.386 & 0.296 & Me 16 & 2,632 & 2.29 & 0.562 & 0.182 \\
\hline Gr 06 & 2,593 & 3.00 & 0.350 & 0.361 & Me 16 & 2,632 & 2.29 & 0.486 & 0.241 \\
\hline Gn 07 & 2,674 & 2.04 & 0.505 & 0.200 & Me 16 & 2,632 & 2.29 & 0.459 & 0.270 \\
\hline Gn 07 & 2,674 & 2.04 & 0.451 & 0.243 & Me 17 & 2,628 & 2.68 & 0.502 & 0.188 \\
\hline Gn 07 & 2,674 & 2.04 & 0.419 & 0.286 & Me 17 & 2,628 & 2.68 & 0.433 & 0.238 \\
\hline Gn 08 & 2,830 & 2.05 & 0.489 & 0.249 & Me 17 & 2,628 & 2.68 & 0.385 & 0.292 \\
\hline Gn 08 & 2,830 & 2.05 & 0.450 & 0.309 & Me 18 & 2,569 & 3.50 & 0.436 & 0.244 \\
\hline Gn 08 & 2,830 & 2.05 & 0.400 & 0.346 & Me 18 & 2,569 & 3.50 & 0.375 & 0.305 \\
\hline Gn 09 & 2,666 & 2.60 & 0.438 & 0.239 & Me 18 & 2,569 & 3.50 & 0.353 & 0.328 \\
\hline Gn 09 & 2,666 & 2.60 & 0.369 & 0.302 & Me 19 & 2,649 & 2.28 & 0.372 & 0.357 \\
\hline Gn 09 & 2,666 & 2.60 & 0.322 & 0.360 & Me 19 & 2,649 & 2.28 & 0.467 & 0.236 \\
\hline Gn 10 & 2,647 & 2.54 & 0.446 & 0.244 & Me 19 & 2,649 & 2.28 & 0.415 & 0.289 \\
\hline Gn 10 & 2,647 & 2.54 & 0.370 & 0.334 & Me 19 & 2,649 & 2.28 & 0.388 & 0.338 \\
\hline
\end{tabular}

range of the analyzed mixtures. In addition, the Geoterm model assumes that the mixture of interest consists of air-saturated, homogeneous and isotropic grains, the mixture phases are randomly distributed and the samples plot are within the external porosity region.

The points in Figure 2 represent measurements of samples at different porosities. To resolve the problem of predicting the thermal conductivity of the whole sample using the ETC and porosity measurements, we adjusted the Geoterm and Korvin models curves, independently, to the measurements of ETC of a same sample.

Figure 3 shows lines drawn between the limits of the Geoterm model that were obtained by varying the factor $p$ in Eq. (13) from 0 to 1 in increments of 0.1 , and Figure 4 shows lines drawn between the limits of the Korvin model that were obtained by varying $t$ in $\mathrm{Eq}$. (2) from -1 to 1 . 


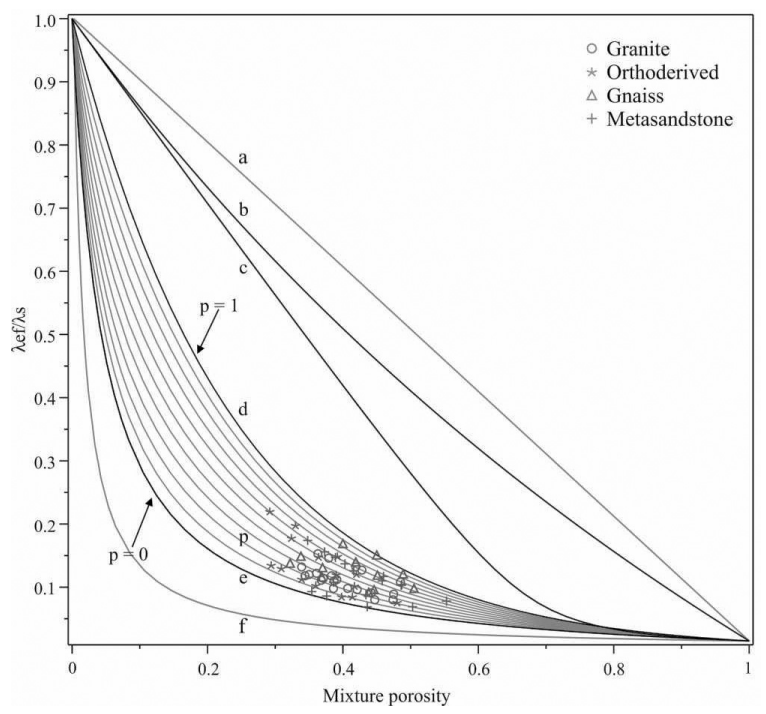

Figure 3 - Illustration of the curves in the region of the Geoterm model obtained by varying the weighting factor $p$ from 0 to 1 in Eq. (13) in increments of 0.1 .

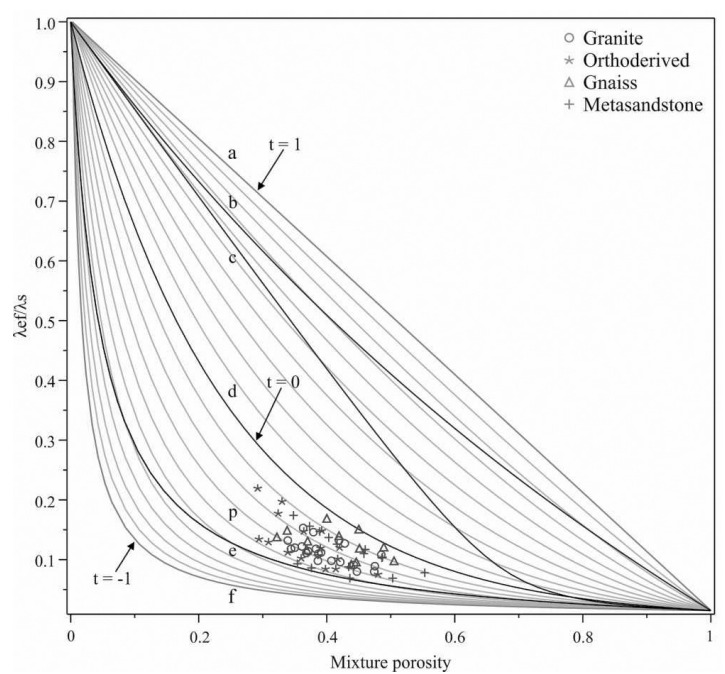

Figure 4 - Illustration of the curves in the region of the Korvin model obtained by varying the distribution factor $t$ from -1 to 1 in Eq. (2) in increments of 0.1 .

To use the Geoterm and Korvin models in the prediction problem (to obtain $\lambda_{s}$ ), we need to choose values for the factors $p$ and $t$ in Eqs. (13) and (2), respectively. We opted to use the average values of $p$ and $t$ that fit the curves of the Eqs. (13) and (2), respectively, in a graph of $\lambda_{e f} \times \phi$ to reproduce $\lambda_{e f}=\lambda_{s}$ at $\phi=0$, taking the air thermal conductivity $\left(\lambda_{a}\right)$ as $0.026 \mathrm{~W} \mathrm{~m}^{-1} \mathrm{~K}^{-1}$ at $\phi=1$.

The adjustment process is exemplified in Figures 5 and 6 . In sample 0r 12 (Fig. 5), $\lambda_{s}=2.01 \mathrm{~W} \mathrm{~m}^{-1} \mathrm{k}^{-1}$ and the curves of the Geoterm and Korvin models are fitted for $\lambda_{e f}=\lambda_{s}$ in the Eqs. (13) and (2) with $p=0.576$ and $t=-0.142$, respectively. For sample Me 17 (Fig. 6) with $\lambda_{s}=2.68 \mathrm{~W} \mathrm{~m}^{-1} \mathrm{k}^{-1}, p=0.505$ and $t=-0.160$.
As seen in Figure 5, all of the adjusted curves fit the experimental points of the samples well, which indicates that both the Geoterm and Korvin models are good heat conduction models for these mixtures for the porosity range used in this study.

Table 2 presents the factors $p$ and $t$ that reproduce the thermal conductivity $\lambda_{s}$ of the whole rock for the Geoterm and Korvin models, respectively. The error associated to $p$ and $t$ is about of 10\%. The ranges of variation of $p$ and $t$ are large: $p$ varies from 0.386 to 1.037 with an average of 0.61 and a relative deviation of $28 \%$, while $t$ varies from -0.225 to 0.015 with an average of -0.13 and a relative deviation of $48 \%$. These variations reflect the broad spectrum of thermal conductivity values for the different lithotypes and for the same type of rock, as has been reported by several authors (e.g., Clauser \& Huenges, 1995; Labani \& Anurup, 2007). All of these studies concluded that a given lithotype cannot be characterized by a single thermal conductivity value.

Figure 7 shows the curves of Eq. (13) for $p=0.61$ and of Eq. (2) for $t=-0.13$ superimposed on the experimental data shown in Figure 2. These curves overlap in the porosity range of our measurements showing that both models are valid.

Using these average values to $p$ and $t$, the $\lambda_{s}$ and $\phi$ values from Table 1 and taking the air thermal conductivity as $0.026 \mathrm{~W} \mathrm{~m}^{-1} \mathrm{~K}^{-1}$, we predict the ETC values using Eq. (13) for $p=0.61$ and Eq. (2) for $t=-0.13$.

In Table 3, using data from Table 1, we show the measured ETC $\left(\lambda_{e f}\right)$ and the predicted ETC $\left(\lambda_{e f p}\right)$ from the inferior Maxwell-Eucken (Eq. (6)), Geometric (Eq. (5)), Geoterm (Eq. (13)) and Korvin (Eq. (2)) models as well as from the Krupiczka (Eq. (10)) and Woodside-Messmer (Eq. (11)) expressions, together with the corresponding differences from the measured values.

Table 3 shows that the smallest differences are associated with the Geoterm and Korvin models and with the WoodsideMessmer empirical expression. This indicates that these models and expression can efficiently measure the ETC of air-saturated binary mixtures of rock grains.

To calculate the predicted thermal conductivity $\left(\lambda_{s p}\right)$ of the whole rock, we make the adjustment shown in Figure 6 but now fixing $p$ as 0.61 and $t$ as -0.13 to obtain $\lambda_{s p}=\lambda_{e f}$ for $\phi=0$. The calculating process is exemplified in Figures 8 and 9. The sample Me 17 (Fig. 8) has $\lambda_{s}=2.68 \mathrm{~W} \mathrm{~m}^{-1} \mathrm{~K}^{-1}$ and $\lambda_{s p}=2.18 \mathrm{~W} \mathrm{~m}^{-1} \mathrm{~K}^{-1}$ for the Geoterm model and $\lambda_{s p}=$ $2.48 \mathrm{~W} \mathrm{~m}^{-1} \mathrm{~K}^{-1}$ for the Korvin model. For the sample Gr 01 (Fig. 9) with $\lambda_{s}=2.11 \mathrm{~W} \mathrm{~m}^{-1} \mathrm{~K}^{-1}, \lambda_{s p}=2.40 \mathrm{~W} \mathrm{~m}^{-1} \mathrm{~K}^{-1}$ for the Geoterm model and $\lambda_{s p}=2.41 \mathrm{~W} \mathrm{~m}^{-1} \mathrm{~K}^{-1}$ for the Korvin model. 


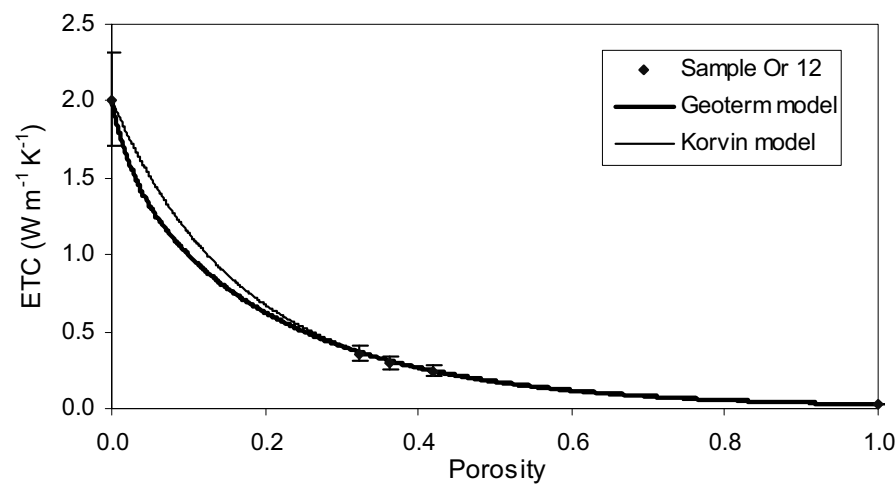

Figure $\mathbf{5}$ - Obtaining the factors $p$ of the Geoterm model and $t$ of the Korvin model by adjusting the curves of these models to the experimental data of sample Or 12 and to the points $\lambda_{e f}=\lambda_{s}$ at $\phi=0$ and $\lambda_{e f}=\lambda_{a}$ at $\phi=1$.

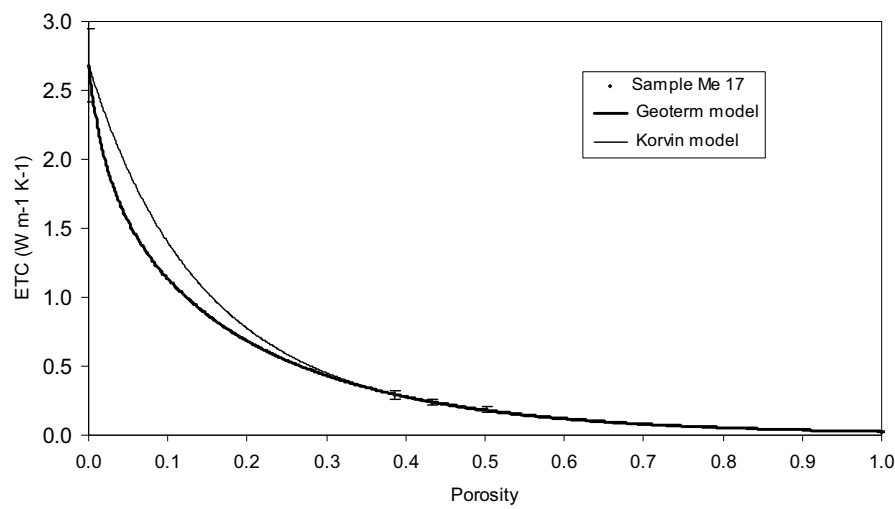

Figure $\mathbf{6}$ - Obtaining the factors $p$ of the Geoterm model and $t$ of the Korvin model by adjusting the curves of these models to the experimental data of sample Me 17 and to the points $\lambda_{e f}=\lambda_{s}$ at $\phi=0$ and $\lambda_{e f}=\lambda_{a}$ at $\phi=1$.

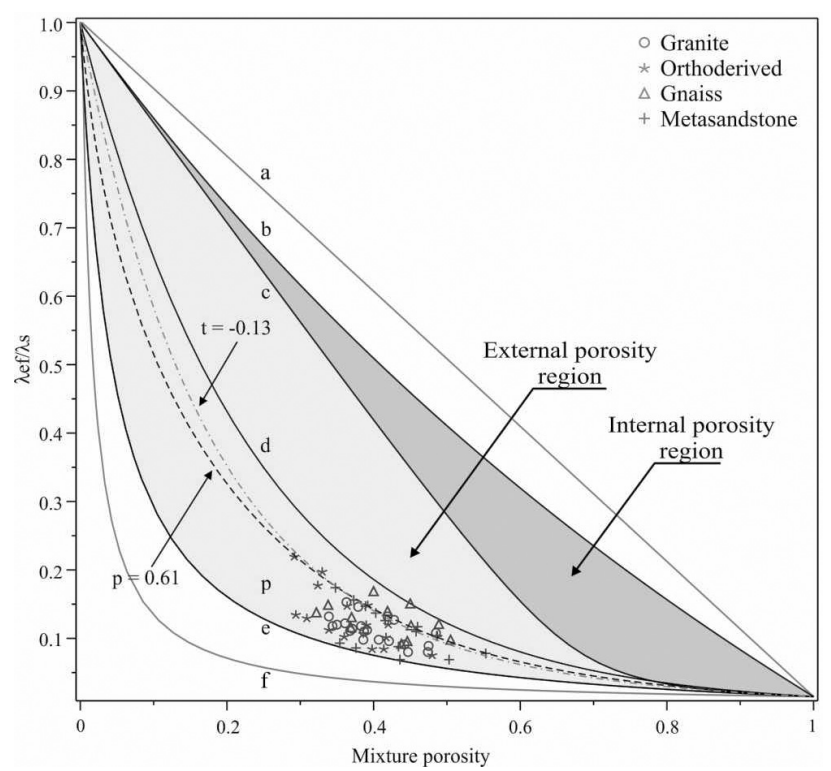

Figure 7 - Curves for $p=0.61$ from Eq. (13) and $t=-0.13$ from Eq. (2) for the Geoterm and Korvin models, respectively, superimposed on the data shown in Figure 2. 
Table 2 - Factors $p$ and $t$ that reproduce the real thermal conductivity in Eqs. (13) and (2), respectively.

\begin{tabular}{|c|c|c|c|}
\hline \multirow{2}{*}{ Sample } & Real value & Geoterm model & Korvin model \\
\cline { 2 - 4 } & $\lambda_{s}, \mathrm{~W} \mathrm{~m}^{-1} \mathrm{k}^{-1}$ & $p$ & $t$ \\
\hline Gr 01 & 2.11 & 0.689 & -0.095 \\
Gr 02 & 2.20 & 0.457 & -0.180 \\
Gr 03 & 2.69 & 0.515 & -0.155 \\
Gr 04 & 2.66 & 0.526 & -0.150 \\
Gr 05 & 2.85 & 0.464 & -0.180 \\
Gr 06 & 3.00 & 0.481 & -0.170 \\
Gn 07 & 2.04 & 0.783 & -0.060 \\
Gn 08 & 2.05 & 1.037 & +0.015 \\
Gn 09 & 2.60 & 0.477 & -0.172 \\
Gn 10 & 2.54 & 0.593 & -0.135 \\
Or 11 & 1.75 & 0.626 & -0.128 \\
Or 12 & 2.01 & 0.576 & -0.142 \\
Or 13 & 3.35 & 0.687 & -0.100 \\
Or 14 & 2.91 & 0.386 & -0.225 \\
Me 15 & 2.19 & 0.730 & -0.080 \\
Me 16 & 2.29 & 0.882 & -0.040 \\
Me 17 & 2.68 & 0.505 & -0.160 \\
Me 18 & 3.50 & 0.386 & -0.214 \\
Me 19 & 2.28 & 0.734 & -0.078 \\
\hline
\end{tabular}

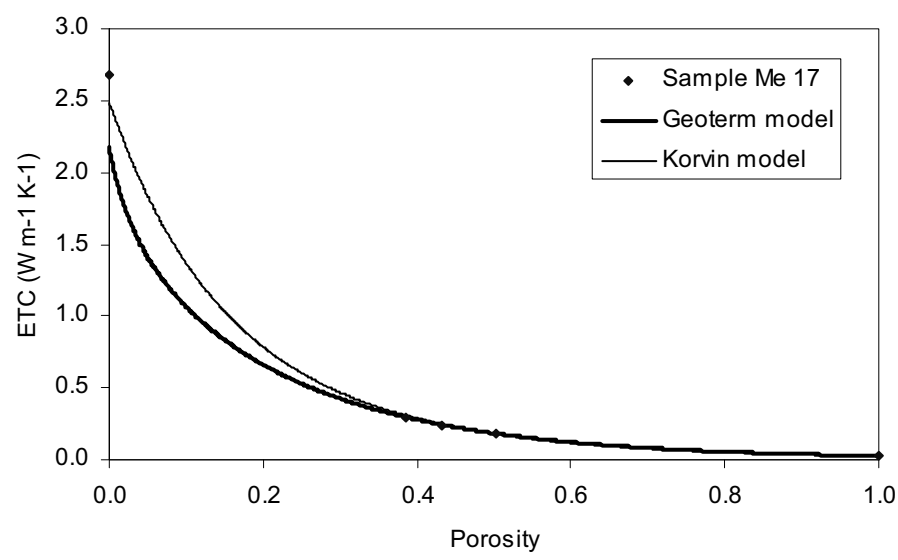

Figure 8 - Adjusting of the curves of the Geoterm model for $p=0.61$ and Korvin model to $t=-0.13$ to the experimental data of the sample Me 17, and to the point $\lambda_{e f}=\lambda_{a}$ in $\phi=1$, to obtain the predicted thermal conductivity $\lambda_{s p}=$ ETC in $\phi=0$.

In Table 4 we present the predicted thermal conductivity of the whole rock obtained with the Geoterm and Korvin models making $p=0.61$ and $t=-0.13$ in their respective equations and their respective discrepancies relative to the real $\lambda_{s}$.

The method developed in this work to obtain the rock thermal conductivity from binary granular mixtures proved effective. The large discrepancies observed in both models is because the
Eqs. (13) and (2) are quite sensitive to the values of $p$ and $t$, respectively, so that values away from the reference values have discrepancies higher; and this not depend of the reference values, but of the width of the range variation of this factors. In the variation range of the porosity of the mixtures in this study, from 0.26 to 0.51 , the curves of the Geoterm and Korvin models practically coincide only differing for porosities below about 0.25 . Getting 
Table 3 - Measured $\left(\lambda_{e f}\right)$ and predicted $\left(\lambda_{e f p}\right)$ ETC values from the models and empirical expressions with the corresponding discrepancies relatives to the measured values. ETC values are in $\mathrm{W} \mathrm{m}^{-1} \mathrm{~K}^{-1}$.

\begin{tabular}{|c|c|c|c|c|c|c|c|c|c|c|c|c|c|}
\hline \multirow{3}{*}{ Sample } & \multirow{2}{*}{ Measured } & \multicolumn{2}{|c|}{ ME-I } & \multicolumn{2}{|c|}{ Geometric } & \multicolumn{2}{|c|}{ Geoterm } & \multicolumn{2}{|c|}{ Korvin } & \multicolumn{2}{|c|}{ Krupiczka } & \multicolumn{2}{|c|}{ Woodside } \\
\hline & & \multicolumn{2}{|c|}{ Eq. (6) } & \multicolumn{2}{|c|}{ Eq. (5) } & \multicolumn{2}{|c|}{ Eq. (13) } & \multicolumn{2}{|c|}{ Eq. (2) } & \multicolumn{2}{|c|}{ Eq. (10) } & \multicolumn{2}{|c|}{ Eq. (11) } \\
\hline & $\lambda_{e f}$ & $\lambda_{e f p}$ & $\delta, \%$ & $\lambda_{e f p}$ & $\delta, \%$ & $\lambda_{e f p}$ & $\delta, \%$ & $\lambda_{e f p}$ & $\delta, \%$ & $\lambda_{e f p}$ & $\delta, \%$ & $\lambda_{e f p}$ & $\delta, \%$ \\
\hline Gr 01 & 0.228 & 0.108 & 52.0 & 0.271 & 19.0 & 0.198 & 13.0 & 0.203 & 0.2 & 0.166 & 27.0 & 0.237 & 3.8 \\
\hline Gr 01 & 0.268 & 0.122 & 54.0 & 0.321 & 20.0 & 0.232 & 13.0 & 0.241 & 10.0 & 0.188 & 30.0 & 0.265 & 1.1 \\
\hline Gr 01 & 0.278 & 0.125 & 55.0 & 0.334 & 20.0 & 0.240 & 14.0 & 0.251 & 10.0 & 0.194 & 30.0 & 0.271 & 2.4 \\
\hline Gr 01 & 0.308 & 0.142 & 54.0 & 0.399 & 29.0 & 0.283 & 8.0 & 0.301 & 2.3 & 0.224 & 27.0 & 0.302 & 2.0 \\
\hline Gr 01 & 0.323 & 0.150 & 54.0 & 0.428 & 32.0 & 0.303 & 6.3 & 0.324 & 0.3 & 0.239 & 26.0 & 0.314 & 2.7 \\
\hline Gr 02 & 0.195 & 0.106 & 46.0 & 0.267 & 37.0 & 0.195 & 0.1 & 0.199 & 2.1 & 0.164 & 16.0 & 0.233 & 19.0 \\
\hline Gr 02 & 0.259 & 0.141 & 46.0 & 0.402 & 55.0 & 0.284 & 9.8 & 0.301 & 16.0 & 0.224 & 13.0 & 0.301 & 16.0 \\
\hline Gr 02 & 0.291 & 0.164 & 44.0 & 0.489 & 68.0 & 0.342 & 18.0 & 0.370 & 27.0 & 0.268 & 8.0 & 0.336 & 16.0 \\
\hline Gr 03 & 0.216 & 0.108 & 50.0 & 0.298 & 38.0 & 0.212 & 1.6 & 0.216 & 0.2 & 0.175 & 19.0 & 0.241 & 11.0 \\
\hline Gr 03 & 0.257 & 0.126 & 51.0 & 0.382 & 48.0 & 0.267 & 3.8 & 0.277 & 7.8 & 0.209 & 19.0 & 0.281 & 9.4 \\
\hline Gr 03 & 0.296 & 0.141 & 52.0 & 0.447 & 51.0 & 0.309 & 4.4 & 0.326 & 10.0 & 0.238 & 20.0 & 0.309 & 4.2 \\
\hline Gr 03 & 0.308 & 0.149 & 52.0 & 0.481 & 56.0 & 0.331 & 7.6 & 0.352 & 14.0 & 0.254 & 18.0 & 0.322 & 4.5 \\
\hline Gr 04 & 0.242 & 0.118 & 51.0 & 0.344 & 42.0 & 0.242 & 0.2 & 0.250 & 3.2 & 0.194 & 20.0 & 0.264 & 9.2 \\
\hline Gr 04 & 0.299 & 0.139 & 54.0 & 0.436 & 46.0 & 0.302 & 1.0 & 0.318 & 6.3 & 0.233 & 22.0 & 0.305 & 1.9 \\
\hline Gr 04 & 0.325 & 0.154 & 53.0 & 0.500 & 54.0 & 0.344 & 5.9 & 0.368 & 13.0 & 0.264 & 19.0 & 0.330 & 1.4 \\
\hline Gr 05 & 0.279 & 0.132 & 53.0 & 0.421 & 51.0 & 0.291 & 4.4 & 0.304 & 8.9 & 0.225 & 19.0 & 0.295 & 5.7 \\
\hline Gr 05 & 0.315 & 0.151 & 52.0 & 0.506 & 61.0 & 0.346 & 9.9 & 0.368 & 17.0 & 0.263 & 17.0 & 0.327 & 3.9 \\
\hline Gr 05 & 0.336 & 0.164 & 51.0 & 0.566 & 69.0 & 0.385 & 15.0 & 0.414 & 23.0 & 0.292 & 13.0 & 0.348 & 3.6 \\
\hline Gr 06 & 0.239 & 0.117 & 51.0 & 0.359 & 50.0 & 0.250 & 4.7 & 0.257 & 7.3 & 0.198 & 17.0 & 0.265 & 11.0 \\
\hline Gr 06 & 0.296 & 0.142 & 52.0 & 0.480 & 63.0 & 0.328 & 11.0 & 0.345 & 17.0 & 0.249 & 16.0 & 0.315 & 6.6 \\
\hline Gr 06 & 0.361 & 0.161 & 55.0 & 0.569 & 58.0 & 0.385 & 6.8 & 0.413 & 14.0 & 0.290 & 20.0 & 0.346 & 4.2 \\
\hline Gn 07 & 0.200 & 0.097 & 51.0 & 0.225 & 13.0 & 0.168 & 16.0 & 0.170 & 15.0 & 0.147 & 27.0 & 0.210 & 4.9 \\
\hline Gn 07 & 0.243 & 0.113 & 53.0 & 0.285 & 17.0 & 0.208 & 14.0 & 0.215 & 12.0 & 0.173 & 29.0 & 0.247 & 1.5 \\
\hline Gn 07 & 0.286 & 0.125 & 56.0 & 0.328 & 15.0 & 0.237 & 17.0 & 0.247 & 14.0 & 0.192 & 33.0 & 0.270 & 5.7 \\
\hline Gn 08 & 0.249 & 0.102 & 59.0 & 0.242 & 2.7 & 0.179 & 28.0 & 0.182 & 27.0 & 0.154 & 38.0 & 0.221 & 11.0 \\
\hline Gn 08 & 0.309 & 0.114 & 63.0 & 0.287 & 7.1 & 0.209 & 32.0 & 0.216 & 30.0 & 0.173 & 44.0 & 0.247 & 20.0 \\
\hline Gn 08 & 0.346 & 0.133 & 62.0 & 0.357 & 3.3 & 0.256 & 26.0 & 0.270 & 22.0 & 0.205 & 41.0 & 0.284 & 18.0 \\
\hline Gn 09 & 0.239 & 0.120 & 50.0 & 0.346 & 45.0 & 0.244 & 2.1 & 0.252 & 5.5 & 0.195 & 18.0 & 0.266 & 11.0 \\
\hline Gn 09 & 0.302 & 0.149 & 51.0 & 0.475 & 57.0 & 0.329 & 8.8 & 0.350 & 16.0 & 0.253 & 16.0 & 0.322 & 6.5 \\
\hline Gn 09 & 0.360 & 0.176 & 51.0 & 0.590 & 64.0 & 0.404 & 12.0 & 0.440 & 22.0 & 0.311 & 14.0 & 0.362 & 0.5 \\
\hline Gn 10 & 0.244 & 0.117 & 52.0 & 0.329 & 35.0 & 0.233 & 4.3 & 0.241 & 1.4 & 0.188 & 23.0 & 0.259 & 6.3 \\
\hline Gn 10 & 0.334 & 0.149 & 56.0 & 0.466 & 40.0 & 0.323 & 3.2 & 0.344 & 3.0 & 0.249 & 25.0 & 0.320 & 4.3 \\
\hline Gn 10 & 0.378 & 0.166 & 56.0 & 0.540 & 43.0 & 0.372 & 1.7 & 0.402 & 6.2 & 0.286 & 24.0 & 0.347 & 8.3 \\
\hline Or 11 & 0.260 & 0.135 & 48.0 & 0.337 & 30.0 & 0.246 & 5.3 & 0.260 & 0.1 & 0.200 & 23.0 & 0.281 & 8.2 \\
\hline Or 11 & 0.346 & 0.166 & 52.0 & 0.438 & 27.0 & 0.316 & 8.8 & 0.342 & 1.0 & 0.254 & 27.0 & 0.327 & 5.4 \\
\hline Or 11 & 0.385 & 0.190 & 51.0 & 0.514 & 34.0 & 0.368 & 4.3 & 0.407 & 5.7 & 0.301 & 22.0 & 0.357 & 7.2 \\
\hline Or 12 & 0.243 & 0.125 & 49.0 & 0.325 & 34.0 & 0.235 & 3.3 & 0.246 & 1.0 & 0.191 & 21.0 & 0.269 & 11.0 \\
\hline Or 12 & 0.298 & 0.150 & 50.0 & 0.415 & 39.0 & 0.295 & 0.9 & 0.316 & 6.0 & 0.234 & 21.0 & 0.311 & 4.4 \\
\hline Or 12 & 0.358 & 0.172 & 52.0 & 0.494 & 38.0 & 0.349 & 2.6 & 0.380 & 6.2 & 0.277 & 23.0 & 0.343 & 4.2 \\
\hline Or 13 & 0.255 & 0.107 & 58.0 & 0.327 & 28.0 & 0.228 & 11.0 & 0.230 & 10.0 & 0.183 & 28.0 & 0.244 & 4.5 \\
\hline Or 13 & 0.341 & 0.130 & 62.0 & 0.444 & 30.0 & 0.302 & 11.0 & 0.313 & 8.3 & 0.229 & 33.0 & 0.294 & 14.0 \\
\hline Or 13 & 0.402 & 0.142 & 65.0 & 0.506 & 26.0 & 0.342 & 15.0 & 0.358 & 11.0 & 0.255 & 36.0 & 0.317 & 21.0 \\
\hline
\end{tabular}

(to be continued) 
Table 3 - (continuation)

\begin{tabular}{|c|c|c|c|c|c|c|c|c|c|c|c|c|c|}
\hline \multirow{3}{*}{ Sample } & \multirow{2}{*}{ Measured } & \multicolumn{2}{|c|}{ ME-I } & \multicolumn{2}{|c|}{ Geometric } & \multicolumn{2}{|c|}{ Geoterm } & \multicolumn{2}{|c|}{ Korvin } & \multicolumn{2}{|c|}{ Krupiczka } & \multicolumn{2}{|c|}{ Woodside } \\
\hline & & \multicolumn{2}{|c|}{ Eq. (6) } & \multicolumn{2}{|c|}{ Eq. (5) } & \multicolumn{2}{|c|}{ Eq. (13) } & \multicolumn{2}{|c|}{ Eq. (2) } & \multicolumn{2}{|c|}{ Eq. (10) } & \multicolumn{2}{|c|}{ Eq. (11) } \\
\hline & $\overline{\lambda_{e f}}$ & $\lambda_{e f p}$ & $\delta, \%$ & $\lambda_{e f p}$ & $\delta, \%$ & $\overline{\lambda_{e f p}}$ & $\delta, \%$ & $\lambda_{e f p}$ & $\delta, \%$ & $\lambda_{e f p}$ & $\delta, \%$ & $\lambda_{e f p}$ & $\delta, \%$ \\
\hline Or 14 & 0.261 & 0.137 & 48.0 & 0.447 & 71.0 & 0.308 & 18.0 & 0.322 & 23.0 & 0.235 & 10.0 & 0.304 & 16.0 \\
\hline Or 14 & 0.392 & 0.198 & 49.0 & 0.730 & 86.0 & 0.491 & 25.0 & 0.543 & 39.0 & 0.377 & 4.0 & 0.396 & 0.9 \\
\hline Or 14 & 0.379 & 0.187 & 51.0 & 0.680 & 80.0 & 0.458 & 21.0 & 0.503 & 33.0 & 0.349 & 8.0 & 0.382 & 0.7 \\
\hline Or 14 & 0.246 & 0.130 & 47.0 & 0.415 & 69.0 & 0.287 & 16.0 & 0.298 & 21.0 & 0.221 & 10.0 & 0.291 & 18.0 \\
\hline Or 14 & 0.299 & 0.156 & 48.0 & 0.535 & 79.0 & 0.364 & 22.0 & 0.388 & 30.0 & 0.275 & 8.0 & 0.336 & 12.0 \\
\hline Or 14 & 0.329 & 0.167 & 49.0 & 0.591 & 80.0 & 0.400 & 22.0 & 0.432 & 31.0 & 0.302 & 8.2 & 0.355 & 7.8 \\
\hline Me 15 & 0.244 & 0.112 & 54.0 & 0.289 & 18.0 & 0.209 & 14.0 & 0.215 & 12.0 & 0.173 & 29.0 & 0.245 & 0.5 \\
\hline Me 15 & 0.303 & 0.132 & 56.0 & 0.368 & 22.0 & 0.262 & 13.0 & 0.276 & 9.0 & 0.209 & 31.0 & 0.286 & 5.6 \\
\hline Me 15 & 0.384 & 0.159 & 59.0 & 0.470 & 22.0 & 0.330 & 14.0 & 0.356 & 7.4 & 0.259 & 33.0 & 0.330 & 14.0 \\
\hline Me 16 & 0.182 & 0.086 & 53.0 & 0.193 & 6.2 & 0.145 & 20.0 & 0.145 & 20.0 & 0.133 & 27.0 & 0.183 & 0.5 \\
\hline Me 16 & 0.241 & 0.103 & 57.0 & 0.260 & 7.8 & 0.189 & 21.0 & 0.193 & 20.0 & 0.160 & 33.0 & 0.227 & 6.0 \\
\hline Me 16 & 0.270 & 0.112 & 59.0 & 0.293 & 8.6 & 0.211 & 22.0 & 0.217 & 20.0 & 0.175 & 35.0 & 0.246 & 9.0 \\
\hline Me 17 & 0.188 & 0.099 & 47.0 & 0.262 & 39.0 & 0.188 & 0.2 & 0.190 & 1.2 & 0.160 & 15.0 & 0.220 & 17.0 \\
\hline Me 17 & 0.238 & 0.122 & 49.0 & 0.360 & 51.0 & 0.253 & 6.2 & 0.261 & 10.0 & 0.200 & 16.0 & 0.272 & 14.0 \\
\hline Me 17 & 0.292 & 0.142 & 51.0 & 0.450 & 54.0 & 0.311 & 6.6 & 0.328 & 12.0 & 0.240 & 18.0 & 0.310 & 6.2 \\
\hline Me 18 & 0.244 & 0.122 & 50.0 & 0.415 & 70.0 & 0.283 & 16.0 & 0.290 & 19.0 & 0.217 & 11.0 & 0.280 & 15.0 \\
\hline Me 18 & 0.305 & 0.149 & 51.0 & 0.557 & 83.0 & 0.373 & 22.0 & 0.392 & 29.0 & 0.275 & 10.0 & 0.331 & 8.5 \\
\hline Me 18 & 0.328 & 0.160 & 51.0 & 0.620 & 89.0 & 0.413 & 26.0 & 0.440 & 34.0 & 0.303 & 7.6 & 0.351 & 6.9 \\
\hline Me 19 & 0.357 & 0.146 & 59.0 & 0.432 & 21.0 & 0.303 & 15.0 & 0.323 & 10.0 & 0.237 & 33.0 & 0.312 & 13.0 \\
\hline Me 19 & 0.236 & 0.109 & 54.0 & 0.282 & 20.0 & 0.204 & 13.0 & 0.209 & 11.0 & 0.170 & 28.0 & 0.240 & 1.6 \\
\hline Me 19 & 0.289 & 0.127 & 56.0 & 0.356 & 23.0 & 0.253 & 12.0 & 0.265 & 8.4 & 0.202 & 30.0 & 0.278 & 3.7 \\
\hline Me 19 & 0.338 & 0.139 & 59.0 & 0.402 & 19.0 & 0.284 & 16.0 & 0.300 & 11.0 & 0.223 & 34.0 & 0.299 & 12.0 \\
\hline
\end{tabular}

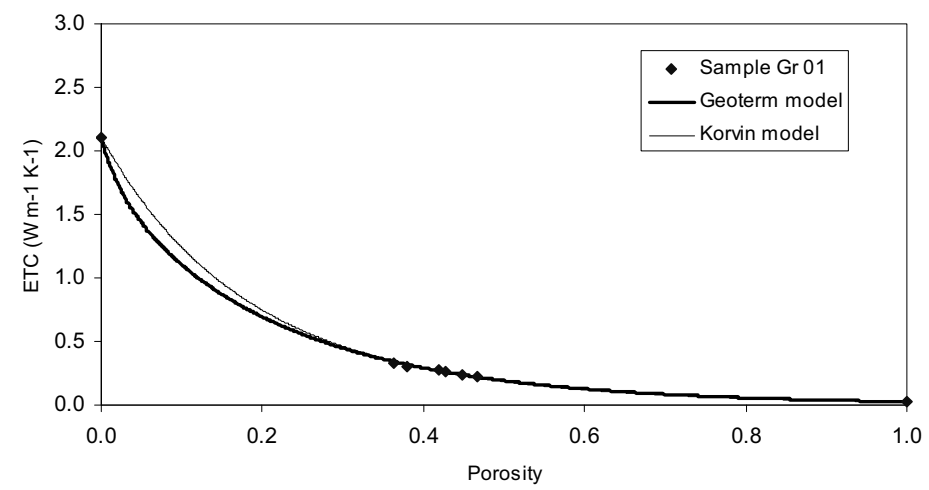

Figure 9 - Adjusting of the curves of the Geoterm model for $p=0.61$ and Korvin model to $t=-0.13$ to the experimental data of the sample Gr 01 , and to the point $\lambda_{e f}=\lambda_{a}$ in $\phi=1$, to obtain the predicted thermal conductivity $\lambda_{s p}=$ ETC in $\phi=0$.

mixtures with porosity below this value is difficult resulting in not have been possible to distinguish between these two models.

These variation ranges of $p$ and $t$ are larges because the thermal conductivity of rock is highly variable. The variability range of thermal conductivity is similar to all analyzed sam- ples and within each lithology. The question is to set up ranges narrower to $p$ and $t$. The next step in this research is, therefore, seek semi-empirical expressions which include the characteristics of the mixtures as well as physical and geological characteristics of the rock. 
Table 4 - Predicted thermal conductivity of the rock fully calculated with the models Geoterm for $p=0.61$ and Korvin for $t=-0.13$ as well as their discrepancies respect of $\lambda_{s}$.

\begin{tabular}{|c|c|c|c|c|c|}
\hline \multirow{2}{*}{ Sample } & Real value & \multicolumn{2}{|c|}{ For $p=0.61$} & \multicolumn{2}{c|}{ For $t=-0.13$} \\
\cline { 2 - 6 } & $\lambda_{s}$ & $\lambda_{s p}$ & $\delta, \%$ & $\lambda_{s p}$ & $\delta, \%$ \\
\hline Gr 01 & 2.11 & 2.40 & 14.0 & 2.41 & 14.0 \\
Gr 02 & 2.20 & 1.66 & 25.0 & 1.70 & 23.0 \\
Gr 03 & 2.69 & 2.20 & 18.0 & 2.30 & 14.0 \\
Gr 04 & 2.66 & 2.25 & 15.0 & 2.40 & 10.0 \\
Gr 05 & 2.85 & 2.14 & 25.0 & 2.20 & 23.0 \\
Gr 06 & 3.00 & 2.32 & 23.0 & 2.36 & 21.0 \\
Gn 07 & 2.04 & 2.70 & 32.0 & 2.90 & 42.0 \\
Gn 08 & 2.05 & 3.83 & 87.0 & 4.30 & 110.0 \\
Gn 09 & 2.60 & 2.03 & 22.0 & 2.00 & 23.0 \\
Gn 10 & 2.54 & 2.42 & 4.7 & 2.58 & 1.5 \\
Or 11 & 1.75 & 1.79 & 2.3 & 1.77 & 1.1 \\
Or 12 & 2.01 & 1.90 & 5.5 & 1.90 & 5.5 \\
Or 13 & 3.35 & 3.88 & 16.0 & 4.20 & 25.0 \\
Or 14 & 2.91 & 1.85 & 36.0 & 1.80 & 38.0 \\
Me 15 & 2.19 & 2.66 & 21.0 & 2.75 & 26.0 \\
Me 16 & 2.29 & 3.63 & 59.0 & 4.30 & 88.0 \\
Me 17 & 2.68 & 2.18 & 19.0 & 2.48 & 7.5 \\
Me 18 & 3.50 & 2.14 & 39.0 & 2.12 & 39.0 \\
Me 19 & 2.28 & 2.79 & 22.0 & 3.10 & 36.0 \\
\hline
\end{tabular}

\section{CONCLUSIONS}

The Geoterm and Korvin heat conduction models showed to be effective in dealing with binary mixtures of rock grains airsaturated because their curves adjusted well to the experimental data of ETT. Moreover, both models showed good results in predicting the ETC measurements in the studied mixtures. Thus, the model and method developed in this work to determine the thermal conductivity of rock from ETC measurements in biphasic granular mixtures was showed to be effective.

The predicted results for the full sample, compared to the measured values, showed discrepancies small and large, a consequence of the range of variation of the thermal conductivity of the rocks to be well large resulting in ranges also large for the numerical factors of the two equations.

The Geoterm and Korvin heat conduction models proved to be effective in dealing with air-saturated binary mixtures of rock grains provided that their curves are adjusted based on ETC measurements. Moreover, both models showed good results in predicting the ETC measurements in the studied mixtures. Thus, the method developed in this work to determine the rock thermal conductivity from ETC measurements in binary granular mixtures was found to be effective.

When compared with the measured thermal conductivity of the solid rock, however, these results are not satisfactory. The $p$ and $t$ factors are highly variable, and the equations of the two models are quite sensitive to variations in these factors. We suggest defining narrower ranges of thermal conductivity values using data from granulated rock samples or drill cuttings.

\section{ACKNOWLEDGEMENTS}

One of the authors (Cardoso) is grateful to the Coordenação de Aperfeiçoamento de Pessoal de Nível Superior (Capes), Brazil, for supporting part of his doctoral studies. This work is part of the Geoterm-Ne project funded by Petrobras-Cenpes-Promob, and by the National Institute of Science and Technology of Petroleum Geophysics - INCT-GP. The authors thank Dr. Olivar A.L. de Lima for his valuable suggestions. 


\section{REFERENCES}

ANAND J, SOMERTON WH \& GOMAA E. 1973. Predicting thermal conductivities of formations from other known properties. Society of Petroleum Engineers Journal, 13: 267-273.

CARSON JK, LOVATT SJ, TANNER DJ \& CLELAND AC. 2005. Thermal conductivity bounds for isotropic, porous materials. International Journal of Heat and Mass Transfer, 48(11): 2150-2158.

CARSONJK, LOVATT SJ, TANNER DJ \& CLELAND AC. 2006. Predicting the effective thermal conductivity of unfrozen, porous foods. Journal of Food Engineering, 75: 297-307.

CLAUSER C \& HUENGES E. 1995. Thermal conductivity of rocks and minerals. In: AHRENS TJ (Ed.). Rock Physics \& Phase Relations: A Handbook of Physical Constants. Washington, DC, American Geophysical Union, Reference Shelf, 3: 105-126.

KORVIN G. 1982. Axiomatic characterization of the general mixture rule. Geoexploration, 19: 267-276.

KRUPICZKA R. 1967. Analysis of thermal conductivity in granular materials. Int. Chem. Eng., 7: 122-144.
LABANI R \& ANURUP B. 2007. Thermal conductivity of Higher Himalayan Crystallines from Garhwal Himalaya, Indian. Tectonophysics, 434: $71-79$.

LANDAUER R. 1952. The electrical resistance of binary metallic mixtures. Journal of Applied Physics, 23: 779-784.

MAXWELL JC. 1954. Treatise on Electricity and Magnetism. 3rd ed., v.1, p. 2, Chapter 9, Dover, New York. 650 pp.

OLIVEIRA NB. 2006. Efeitos do gradiente do campo magnético na determinação da porosidade por ressonânciamagnética nuclear. Doctorate thesis, Universidade Federal da Bahia, Brazil, 114 pp. Available on: <http://www.pggeofisica.ufba.br/teses>. Access on: May 16, 2013.

TAVMAN $\mathbb{H}$. 1996. Effective thermal conductivity of granular porous materials. Int. Comm. Heat Mass Transfer, 23(2): 169-176.

TENCHOV GG. 1998. Evaluation of electrical conductivity of shaly sands using the theory of mixtures. Journal of Petroleum Science and Engineering, 21: 263-271.

WOODSIDE W \& MESSMER JH. 1961. Thermal conductivity of porous media. Journal of Applied Physics, 32(9): 1688-1706.

Recebido em 19 novembro, 2013 / Aceito em 27 fevereiro, 2015

Received on November 19, 2013 / Accepted on February 27, 2015

\section{NOTES ABOUT THE AUTHORS}

Ariston de Lima Cardoso is BS in Physics from the Universidade Federal da Bahia (2003), MSc in Physics (2007) and PhD in Geophysics from the Universidade Federal da Bahia (2013). Currently, is an Adjunct Professor at the Center for Physical Sciences and Technology of the Universidade Federal do Recôncavo da Bahia. Current research interests involve thermal properties of rocks, blends systems and complex networks.

Roberto Max de Argollo is BS in Physics from the Universidade do Brasil (now UFRJ) (1963), MSc in Oceanography, University of Rhode Island, USA (1974) and $\mathrm{PhD}$ in Geophysics from the Universidade Federal da Bahia (2001). Is a retired full professor of the Physics Institute of the Universidade Federal da Bahia where remains bound to the postgraduate degree in Geophysics and as researcher at the Center for Research in Geophysics and Geology both of the Universidade Federal da Bahia. Current research interests involve thermal properties of rocks, radiogenic heat production in rocks and thermal structure of the lithosphere.

Alexandre Barreto Costa is BS in Physics from the Universidade Federal da Bahia (1997), MSc and PhD in Geophysics from the Universidade Federal da Bahia (2001/2006). Currently, is an Assistant Professor at UFBA. Has experience in Nuclear Geophysics, acting on the following topics: gamma spectrometry of sediments and rocks; radioactivity in groundwater; 14-Carbon dating; stable isotopes applied to water, organic matter and coral; and elementary analysis. Interest in the determination of radiogenic heat of rocks using gamma spectrometry measurements and thermal properties of rocks. 